\title{
The Associations between Toll-Like Receptor 9 Gene Polymorphisms and Cervical Cancer Susceptibility
}

\author{
Sijuan Tian, ${ }^{1}$ Liping Zhang, ${ }^{2}$ Ting Yang, ${ }^{1}$ Xing Wei, ${ }^{1}$ Li Zhang, ${ }^{1}$ Yang Yu, ${ }^{1}$ Yang Li, ${ }^{1}$ Di Cao, ${ }^{1}$ \\ and Xiaofeng Yang ${ }^{1}{ }^{1}$ \\ ${ }^{1}$ Department of Obstetrics and Gynecology, The First Affiliated Hospital of Xi'an Jiaotong University, 277 West Yanta Road, Xi'an, \\ Shaanxi 710061, China \\ ${ }^{2}$ Department of Obstetrics and Gynecology, Taihe Hospital, Hubei University of Medicine, Shiyan, Hubei 442000, China
}

Correspondence should be addressed to Xiaofeng Yang; yxf73@163.com

Received 28 January 2018; Accepted 27 June 2018; Published 25 July 2018

Academic Editor: Giuseppe Valacchi

Copyright (c) 2018 Sijuan Tian et al. This is an open access article distributed under the Creative Commons Attribution License, which permits unrestricted use, distribution, and reproduction in any medium, provided the original work is properly cited.

\begin{abstract}
This meta-analysis systematically reviews the association between Toll-like receptor 9 polymorphisms and the risk of cervical cancer. Case-control studies focused on the association were collected from the PubMed, Web of Science, Cochrane Library, Embase, MEDLINE, CNKI, VIP, and Wanfang databases from inception to July 2017. We screened the studies and assessed the methodological quality of the included studies and extracted data. A meta-analysis was performed using RevMan 5.3 and Stata 12.0 software. Pooled odds ratios and $95 \%$ confidence intervals were employed to evaluate the strength of the associations between Toll-like receptor 9 polymorphisms and cervical cancer risk. A total of 9 studies comprising 3331 cervical cancer patients and 4109 healthy controls met the inclusion criteria. Of these, 8 studies contained information about G2848A (rs352140) and 4 studies contained information about $-1486 \mathrm{~T} / \mathrm{C}$ (rs187084). Our results revealed that the associations between rs187084 and cervical cancer risk in the dominant model $(p=0.002)$ and heterozygous model $(p=0.002)$ were significant, with 1.30 - and 1.32-fold increases in susceptibility, respectively, compared to that in the wild-type model. However, rs 352140 was not related to cervical cancer regardless of whether the subgroup analysis was conducted $(p>0.05)$. In conclusion, there is a significant correlation between rs 187084 and cervical cancer risk with the minor $\mathrm{C}$ allele increasing the risk of occurrence of cervical cancer. However, rs352140 is not associated with the occurrence of cervical cancer.
\end{abstract}

\section{Introduction}

Cervical cancer is the fourth most common cancer in women in terms of both incidence and mortality worldwide [1]. According to global cancer statistics, there were approximately 527,600 new cervical cancer cases and 265,700 deaths in 2012. In low-income countries, cervical cancer ranks as second in incidence and is the third leading cause of cancerassociated death among women. In China, the estimated new cancer cases and deaths were 98,900 and 30,500, respectively, in 2015, presenting an upward trend $[2,3]$. Human papillomavirus (HPV) was identified as a principal cause of cervical cancer $[4,5]$. However, $90 \%$ of HPV genital infections can be spontaneously cleared, and few of these progress to cervical cancer [6], suggesting that other pathogeneses and aetiologies might contribute to cervical carcinogenesis.
Toll-like receptors (TLRs) are transmembrane proteins that recognize pathogen-associated molecular patterns (PAMPs), conserved structural motifs in bacteria, fungi, and viruses [7]. TLRs initiate the innate immune response and further modulate acquired immune response, playing an important role in inflammation and carcinogenesis. TLR9 recognizes nonmethylated CpG islands in viral DNA and activates the immune system. In the past few years, evidence suggests that TLR9 expression increases according to the histopathological grade of the cervical pathological process and the HPV E6 and E7 oncoproteins deregulate the expression and function of TLR9 $[8,9]$.

It has been noted that the TLR 9 gene is polymorphic and associated with various cancers, including cervical cancer, prostate cancer, oesophageal cancer, gastric cancer, breast cancer, colorectal carcinoma, and lymphoma [10]. Many 
single-nucleotide polymorphisms (SNPs) of TLR9 have been studied, including rs352140, rs187084, rs352149, rs445676, and rs5743836, according to the NCBI database (https:// www.ncbi.nlm.nih.gov/snp). Among these SNPs, two prominent variants, namely, rs352140 (G2848A) and rs187084 $(-1486 \mathrm{~T} / \mathrm{C})$, are frequently observed to be related to cervical cancer susceptibility. However, the results are contentious. Therefore, we conducted this meta-analysis to estimate the association between cervical cancer risk and the most concerning two SNPs of TLR9, rs352140 and rs187084.

\section{Materials and Methods}

2.1. Literature Search Strategy. We reviewed the PubMed, Web of Science, the Cochrane Library, Embase, MEDLINE, CNKI, VIP, and Wanfang databases systematically and comprehensively. The search terms are the following: Toll-Like Receptors [Mesh] or TLR*, polymorphism*/variant*/mutation*/SNP, Uterine Cervical Neoplasm [Mesh]/cervix cancer/cervical cancer, and the combinations of these. Additionally, we searched the reference lists of all identified articles manually for more studies.

2.2. Inclusion and Exclusion Criteria. Studies included needed to meet the following criteria: (1) a focus on the association between the TLR9 gene polymorphisms (rs352140 and rs187084) and the risk of cervical cancer, (2) human study subjects, (3) case-control studies, (4) available and sufficient genotype distribution of data to calculate odds ratios (ORs) and corresponding 95\% confidence intervals (CIs), and (5) diagnoses based on cervical biopsy pathology. Additionally, if there were duplicate studies, we made sure that the most recent or the most complete one was included. If it did not satisfy the criteria above, the article was excluded.

2.3. Data Extraction and Synthesis. Two investigators extracted relevant data from all the eligible studies independently. A third reviewer was invited to participate in the work when some disagreement occurred; consensus was ultimately reached by discussion. These characteristics were collected from each study: the first author, publication year, race, total numbers of cases and controls, study design, source of controls, genotyping method, and evidence of HWE in controls.

2.4. Quality Assessment. The quality of included studies was assessed using the Newcastle-Ottawa scale, including three categories: selection, comparability, and outcome. Additional eight items were used to assess the methodology of each qualified study. The highest score was 9. Studies with a score of more than 7 were considered as high quality. A study awarded a score of $0-3,4-6$, or 7-9 was considered as a low-, moderate-, or high-quality study, respectively.

2.5. Statistical Analysis. The odds ratios (ORs) and 95\% confidence interval (CIs) were applied to assess the strength of the correlation between SNPs and cervical cancer susceptibility. A $Z$-test revealed statistical significance when $p<0.05$. $I^{2}$ and $Q$ statistics were employed to detect heterogeneity among different studies. There was no heterogeneity if $I^{2}<50 \%$ and $p>0.1$ and a fixed effects model was used; otherwise, we thought that heterogeneity existed in the incorporated populations and a random effects model was used instead. Subsequently, we conducted a subgroup analysis according to race. HardyWeinberg equilibrium (HWE) was evaluated by $\chi^{2}$ test in control groups with $p<0.05$ indicating a deviation from HWE. Sensitivity analysis was utilized to estimate the robustness and stability of the meta-analysis results by deleting all the studies one by one. Next, Begg's funnel plot and Egger's test were used to evaluate publication bias. For each SNP, five genetic models were evaluated to assess the correlation with cervical cancer susceptibility: the allele model, dominant model, recessive model, heterozygote model, and homozygous model. The statistical analyses were performed using RevMan 5.3 and Stata 12.0 software. All $p$ values were two sided, and $p<0.05$ was considered to be statistically significant.

\section{Results}

3.1. Characteristics of Included Studies. By searching the electronic databases systematically, we initially retrieved 72 articles (Figure 1). After excluding duplicate studies, 32 articles remained. Further reviewing of the titles and abstracts of the identified studies allowed the removal of 22 articles. Of those removed, 16 were clearly irrelevant to TLR9 polymorphisms, 4 were review papers, and 2 were meta-analyses. We downloaded the remaining 10 articles as full-text reports and reviewed them carefully. One record was excluded for containing duplicate samples. Finally, 9 case-control studies containing 3331 cases and 4109 controls were included in the meta-analysis, among which 8 studies were about rs352140 (G2848A) and 4 articles were about rs187084 ( $-1486 \mathrm{~T} / \mathrm{C})$. All studies were based on Caucasian or Chinese Han populations.

These 9 case-control studies were published between 2011 and 2017. Four studies were performed with Caucasians, while five papers were based on Chinese Han populations. All the studies were performed using PCR-RFLP to identify the polymorphism sites except two studies, which used the TaqMan and Illumina GoldenGate methods. Two of the nine control groups were hospital-based groups, while the rest were population-based groups (Table 1).

We applied the Newcastle-Ottawa scale (NOS) to estimate the quality of the nine included studies [20]. The results showed that all studies were of high quality (Table 1 ). The distributions of the genotypes and allele frequencies of rs352140 (G2848A) and rs187084 (-1486T/C) are shown in Table 2. The distributions of the genotypes in the nine control groups were in accordance with Hardy-Weinberg equilibrium (HWE) except for two studies $[15,16]$ (Table 2).

3.2. Meta-Analysis Results. There were 8 studies on rs 352140 that included 2619 cases and 3392 healthy controls. The meta-analysis results did not show a statistical relationship between rs352140 and the risk of cervical cancer in any of the five genetic models: allele model $(\mathrm{OR}=1.20, p=0.09)$ (Figure 2), dominant model $(\mathrm{OR}=1.30, p=0.08)$, recessive model $(\mathrm{OR}=1.23, p=0.34)$, heterozygote model $(\mathrm{OR}=1.24$, 


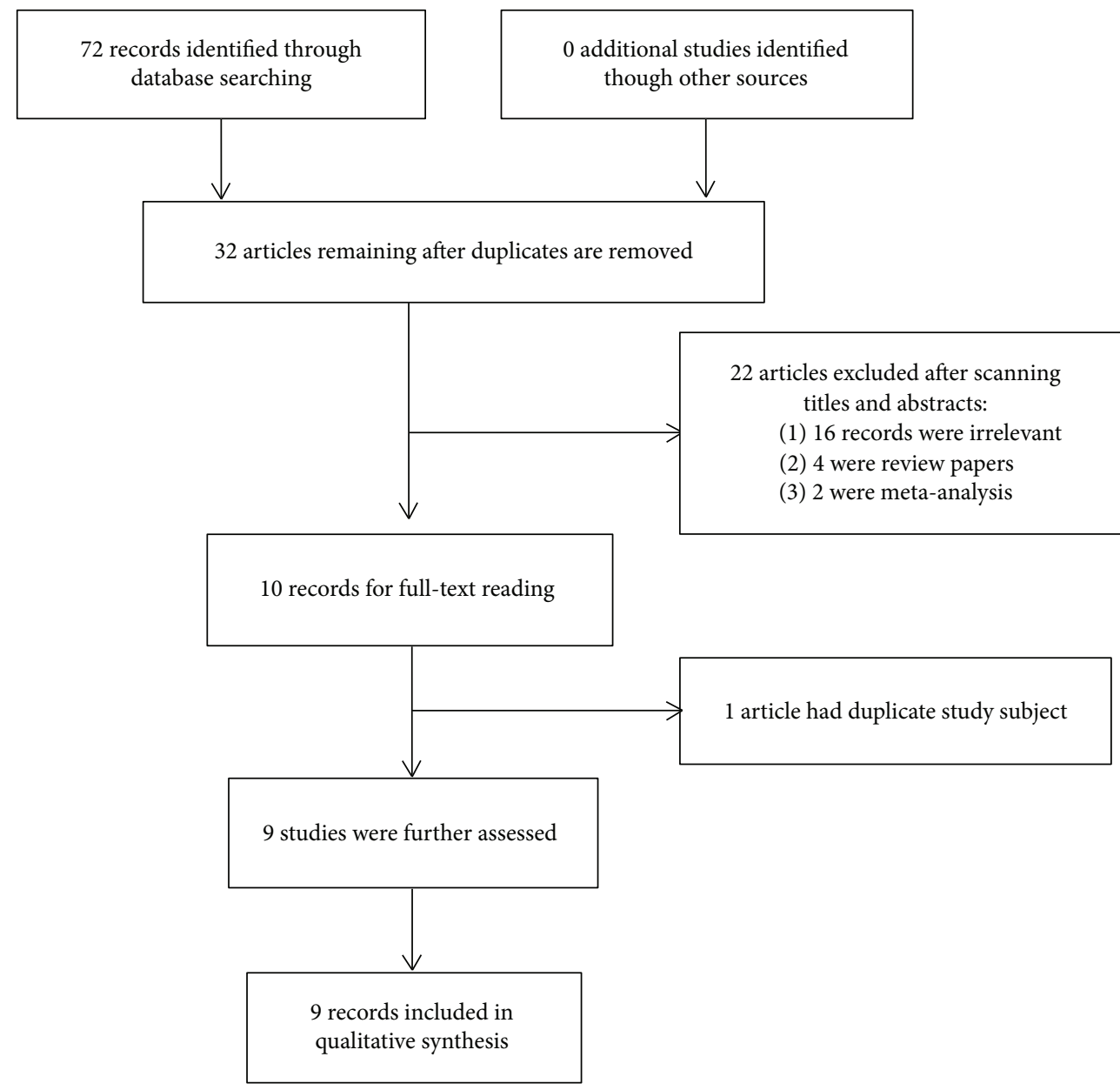

FIGURE 1: Flow diagram of searching procedure.

TABLE 1: Characteristics of the included studies.

\begin{tabular}{|c|c|c|c|c|c|c|c|}
\hline First author & Year & Race & Number (case/control) & Study design & Source of controls & Genotyping method & Study quality (NOS) \\
\hline $\mathrm{Bi}[11]$ & 2014 & Chinese Han & $102 / 100$ & $\mathrm{CC}$ & Population & PCR-RFLP & 7 \\
\hline Bodelon [12] & 2014 & Caucasian & $876 / 1100$ & $\mathrm{CC}$ & Population & Illumina GoldenGate & 8 \\
\hline Chen [13] & 2012 & Chinese Han & $712 / 717$ & $\mathrm{CC}$ & Population & PCR-RFLP & 7 \\
\hline Jin [14] & 2017 & Chinese Han & $420 / 842$ & $\mathrm{CC}$ & Hospital & PCR-RFLP & 7 \\
\hline Lai [15] & 2013 & Chinese Han & $120 / 100$ & CC & Hospital & PCR-RFLP & 8 \\
\hline Pandey [16] & 2011 & Caucasian & $200 / 200$ & $\mathrm{CC}$ & Population & PCR-RFLP & 7 \\
\hline Roszak [17] & 2012 & Caucasian & $426 / 460$ & $\mathrm{CC}$ & Population & PCR-RFLP & 7 \\
\hline $\mathrm{Xu}[18]$ & 2017 & Chinese Han & $345 / 330$ & $\mathrm{CC}$ & Population & TaqMan & 7 \\
\hline Zidi [19] & 2016 & Caucasian & $130 / 260$ & $\mathrm{CC}$ & Population & PCR-RFLP & 8 \\
\hline
\end{tabular}

CC: case-control; PCR: polymerase chain reaction; RFLP: restriction fragment length polymorphism.

$p=0.10)$, or homozygous genetic model $(\mathrm{OR}=1.34, p=0.23)$ (Table 3). Considering the heterogeneity among studies, a subgroup analysis was performed and stratified by race. As presented in Table 3, the results were still stable $(p>0.05)$, but the A allele was correlated to increasing cervical cancer susceptibility in Caucasians based on the allele genetic model $(\mathrm{OR}=1.11, p=0.03)$ (Figure 3$)$. After excluding the two studies that were not in accordance with HWE, the pooled results did not change (data not shown).

With regard to rs 187084 , there were 4 records involving 1342 cases and 1375 controls. The pooled ORs suggested a significant association between the SNP and cervical cancer risk: allele model $(\mathrm{OR}=1.15, p=0.02)$, dominant model $(\mathrm{OR}=1.30, p=0.002)$ (Figure 4$)$, and heterozygote model 
TABLE 2: TLR9 polymorphism genotype distribution and allele frequency in cases and controls.

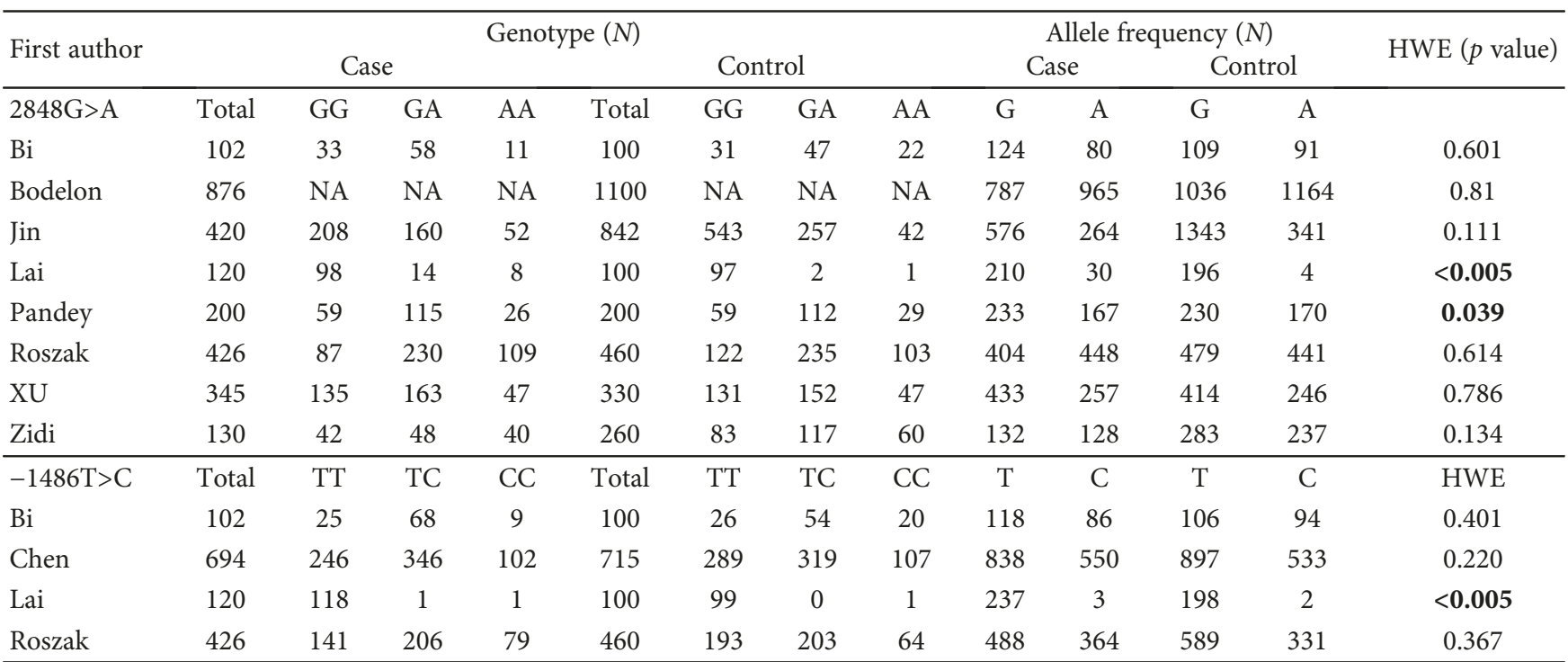

HWE: Hardy-Weinberg equilibrium.

\begin{tabular}{|c|c|c|c|c|c|c|c|}
\hline \multirow{2}{*}{ Study or subgroup } & \multicolumn{2}{|c|}{ Case } & \multicolumn{2}{|c|}{ Control } & \multirow{2}{*}{ Weight } & \multirow{2}{*}{$\begin{array}{l}\text { Odds ratio } \\
\mathrm{M}-\mathrm{H} \text {, random, } 95 \% \mathrm{CI}\end{array}$} & \multirow{2}{*}{$\begin{array}{c}\text { Odds ratio } \\
\mathrm{M}-\mathrm{H} \text {, random, } 95 \% \mathrm{CI} \\
\end{array}$} \\
\hline & Events & Total & Events & Total & & & \\
\hline Bi et al. 2014 & 80 & 204 & 91 & 200 & $10.5 \%$ & $0.77(0.52,1.15)$ & $\rightarrow$ \\
\hline Bodelon et al. 2014 & 965 & 1752 & 1164 & 2200 & $16.2 \%$ & $1.09(0.96,1.24)$ & \\
\hline Jin et al. 2017 & 264 & 840 & 341 & 1684 & $15.0 \%$ & $1.81(1.50,2.18)$ & - \\
\hline Lai et al. 2013 & 30 & 240 & 4 & 200 & $3.1 \%$ & \multirow{2}{*}{$7.00(2.42,20.23)$} & \multirow{2}{*}{$\perp$} \\
\hline Pandey et al. 2011 & 167 & 400 & 170 & 400 & $13.0 \%$ & & \\
\hline Roszak et al. 2012 & 448 & 852 & 441 & 920 & $15.1 \%$ & $1.20(1.00,1.45)$ & - \\
\hline Xu et al. 2017 & 257 & 690 & 246 & 660 & $14.4 \%$ & $1.00(0.80,1.25)$ & $\rightarrow$ \\
\hline Zidi et al. 2016 & 128 & 260 & 237 & 520 & $12.7 \%$ & $1.16(0.86,1.56)$ & - \\
\hline \multicolumn{2}{|l|}{ Total $(95 \%$ CI $)$} & 5238 & & 6784 & $100.0 \%$ & $1.20[0.97,1.47]$ & 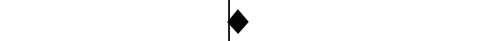 \\
\hline \multirow{2}{*}{\multicolumn{7}{|c|}{$\begin{array}{l}\text { Heterogeneity: } \operatorname{tau}^{2}=0.06 ; \mathrm{chi}^{2}=40.46, \mathrm{df}=7(p<0.00001) ; I^{2}=83 \% \\
\text { Test for overall effect: } Z=1.70(p=0.09)\end{array}$}} & \\
\hline & & & & & & & $1 \quad 10 \quad 100$ \\
\hline
\end{tabular}

FIGURE 2: Forest plots of the association between TLR9 rs352140 polymorphism and cervical cancer risk in the allele genetic model.

$(\mathrm{OR}=1.32, p=0.002)$; nevertheless, it was not related to cancer susceptibility on the recessive model or homozygous genetic model $(p>0.05)$ (Table 4$)$. We then performed subgroup analysis based on ethnicity to reassess the relationship between rs187084 and cervical cancer risk. The results were stable. Data revealed that TLR9 rs187084 was related to cervical cancer risk of Chinese Han population in the dominant model ( $\mathrm{OR}=1.22, p=0.05)$ (Figure 5) and heterozygous genetic model $(\mathrm{OR}=1.28, p=0.02)$. There was no statistical correlation in the recessive model $(\mathrm{OR}=0.70, p=0.34)$ or homozygous genetic model $(\mathrm{OR}=0.88, p=0.67$ ) (Figure 6 , Table 4). Furthermore, the same results were present after eliminating a study that deviated from HWE.

With regard to rs187084, there were 4 records involving 1342 cases and 1375 controls. The pooled ORs suggested a significant association between the SNP and cervical cancer risk: allele model $(\mathrm{OR}=1.15, p=0.02)$, dominant model $(\mathrm{OR}=1.30, p=0.002)$ (Figure 4$)$, and heterozygote model $(\mathrm{OR}=1.32, p=0.002)$. However, the SNP was not related to cancer susceptibility in the recessive model or homozygous genetic model $(p>0.05)$ (Table 4$)$. We performed a subgroup analysis based on race to reassess the relationship between rs187084 and cervical cancer risk; the results were stable. Data revealed that TLR9 rs187084 was related to cervical cancer risk in the Chinese Han population in the dominant model $(\mathrm{OR}=1.22, p=0.05)$ (Figure 5) and heterozygous genetic model $(\mathrm{OR}=1.28, p=0.02)$. There was no statistical correlation in the recessive model $(\mathrm{OR}=0.70, p=0.34)$ or homozygous genetic model $(\mathrm{OR}=0.88, p=0.67$ ) (Figure 6, Table 4). Furthermore, the same results were present after eliminating a study that deviated from HWE.

3.3. Detection for Heterogeneity. As presented in Table 3, there was great heterogeneity among studies relating to rs352140 in all genetic models $\left(I^{2}>50 \%, p<0.1\right)$. In consideration of this, we employed a random effects model for the meta-analysis. Additionally, the subgroup analysis was stratified by race to eliminate heterogeneity (Figure 3). It was clearly decreased in Caucasians as shown: allele model $\left(I^{2}=0 \%, p=0.62\right)$, dominant model $\left(I^{2}=17 \%, p=0.30\right)$, recessive model $\left(I^{2}=0 \%, p=0.39\right)$, heterozygote model $\left(I^{2}=38 \%, p=0.20\right)$, and homozygous 
TABLE 3: Meta-analysis results of rs352140 based on five genetic models.

\begin{tabular}{|c|c|c|c|c|c|}
\hline \multirow{2}{*}{ Genetic models } & \multirow{2}{*}{ OR $(95 \% \mathrm{CI})$} & \multirow{2}{*}{$p$ value } & \multicolumn{2}{|c|}{ Heterogeneity } & \multirow{2}{*}{ Effects model } \\
\hline & & & $I^{2}(\%)$ & $p$ value & \\
\hline \multicolumn{6}{|c|}{ Allele model (A versus $G$ ) } \\
\hline Overall & $1.20(0.97,1.47)$ & 0.09 & 83 & 0.00001 & $\mathrm{R}$ \\
\hline \multicolumn{6}{|l|}{ Race } \\
\hline Chinese Han & $1.46(0.86,2.48)$ & 0.16 & 91 & $<0.0001$ & $\mathrm{R}$ \\
\hline Caucasian & $1.11(1.01,1.22)$ & 0.03 & $\mathbf{0}$ & 0.62 & $\mathrm{R}$ \\
\hline \multicolumn{6}{|c|}{ Dominant model (AA + GA versus GG) } \\
\hline Overall & $1.30(0.97,1.74)$ & 0.08 & 73 & 0.001 & $\mathrm{R}$ \\
\hline \multicolumn{6}{|l|}{ Race } \\
\hline Chinese Han & $1.54(0.91,2.61)$ & 0.11 & 83 & 0.0006 & $\mathrm{R}$ \\
\hline Caucasian & $1.17(0.91,1.49)$ & 0.22 & 17 & 0.30 & $\mathrm{R}$ \\
\hline \multicolumn{6}{|c|}{ Recessive model (AA versus GA + GG) } \\
\hline Overall & $1.23(0.81,1.86)$ & 0.34 & 77 & 0.0002 & $\mathrm{R}$ \\
\hline \multicolumn{6}{|l|}{ Race } \\
\hline Chinese Han & $1.35(0.54,3.39)$ & 0.52 & 87 & $<0.0001$ & $\mathrm{R}$ \\
\hline Caucasian & $1.20(0.94,1.51)$ & 0.14 & $\mathbf{0}$ & 0.39 & $\mathrm{R}$ \\
\hline \multicolumn{6}{|c|}{ Heterozygous genetic model (GA versus GG) } \\
\hline Overall & $1.24(0.96,1.59)$ & 0.10 & 58 & 0.03 & $\mathrm{R}$ \\
\hline \multicolumn{6}{|l|}{ Race } \\
\hline Chinese Han & $1.42(0.94,2.15)$ & 0.09 & 67 & 0.03 & $\mathrm{R}$ \\
\hline Caucasian & $1.09(0.81,1.49)$ & 0.56 & 38 & 0.20 & $\mathrm{R}$ \\
\hline \multicolumn{6}{|c|}{ Homozygous genetic model (AA versus GG) } \\
\hline Overall & $1.34(0.83,2.15)$ & 0.23 & 78 & 0.0001 & $\mathrm{R}$ \\
\hline \multicolumn{6}{|l|}{ Race } \\
\hline Chinese Han & $1.53(0.57,4.15)$ & 0.40 & 88 & $<0.0001$ & $\mathrm{R}$ \\
\hline Caucasian & $1.30(0.98,1.73)$ & 0.07 & $\mathbf{0}$ & 0.42 & $\mathrm{R}$ \\
\hline
\end{tabular}

F: fixed-effect model; R: random-effect model; OR: odds ratio; 95\% CI: 95\% confidence interval.

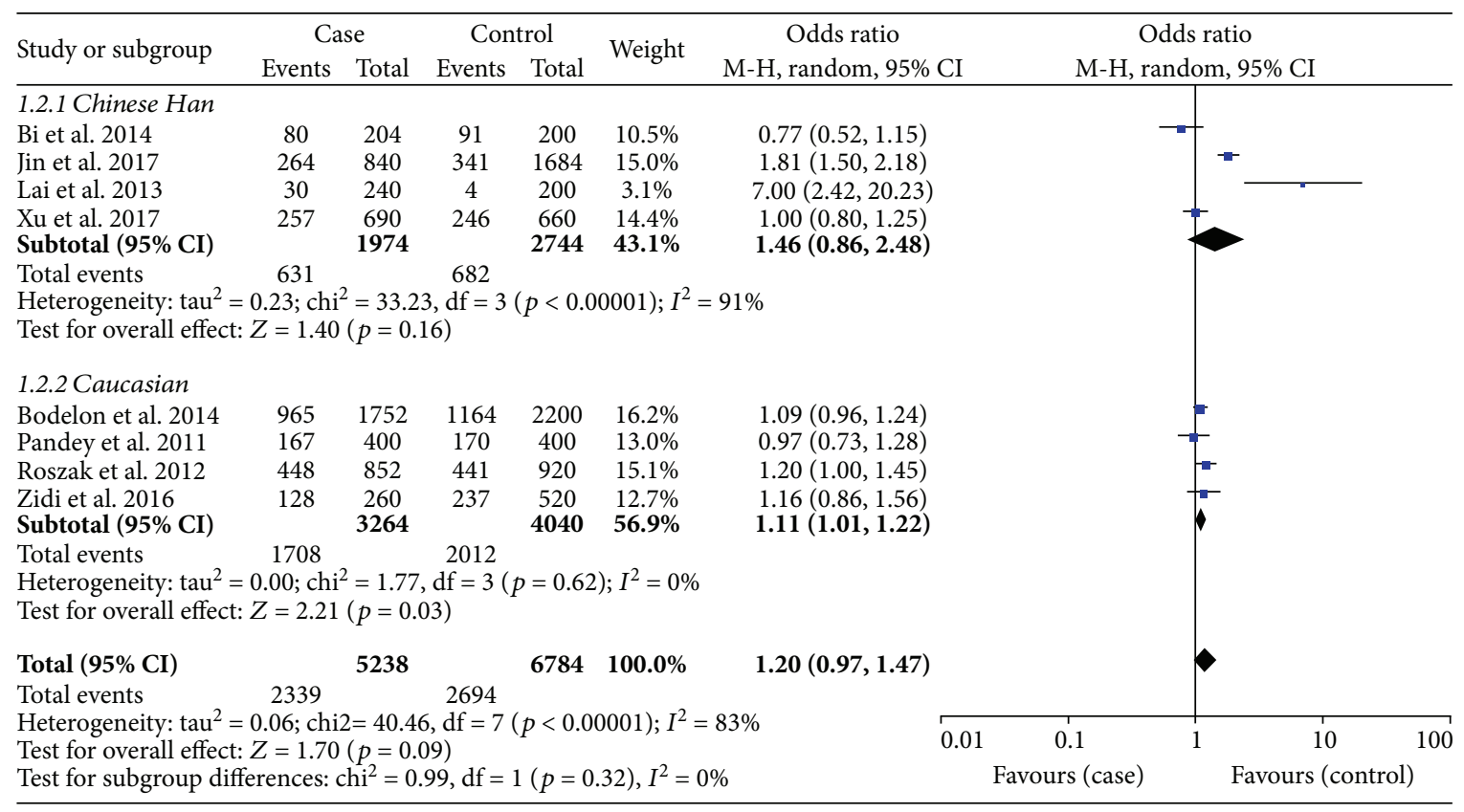

FIGURE 3: Subgroup analysis of the association between TLR9 rs352140 polymorphism and the risk of cervical cancer stratified by race in the allele genetic model. 


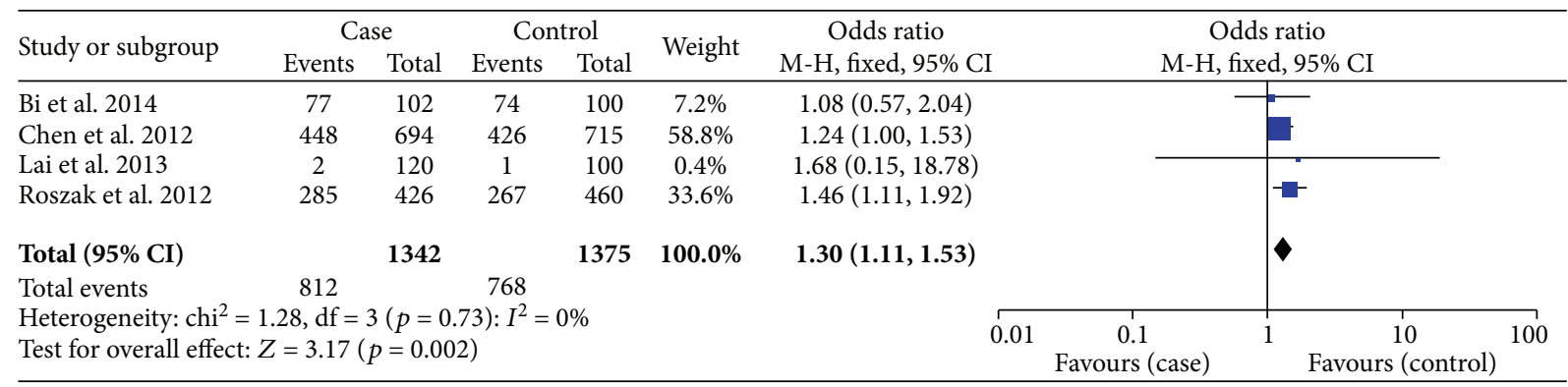

FIgURE 4: Forest plots of the association between TLR9 rs187084 polymorphism and cervical cancer risk in the dominant genetic model.

TABLE 4: Meta-analysis results of rs187084 based on five genetic models.

\begin{tabular}{|c|c|c|c|c|c|}
\hline \multirow{2}{*}{ Genetic models } & \multirow{2}{*}{ OR $(95 \% \mathrm{CI})$} & \multirow{2}{*}{$p$ value } & \multicolumn{2}{|c|}{ Heterogeneity } & \multirow{2}{*}{ Effects model } \\
\hline & & & $I^{2}(\%)$ & $p$ value & \\
\hline \multicolumn{6}{|c|}{ Allele model (C versus $\mathrm{T})$} \\
\hline Overall & $1.15(1.03,1.29)$ & 0.02 & 43 & 0.15 & $\mathrm{~F}$ \\
\hline \multicolumn{6}{|l|}{ Race } \\
\hline Chinese Han & $1.06(0.92,1.23)$ & 0.39 & 0 & 0.38 & $\mathrm{~F}$ \\
\hline Caucasian & $1.33(1.10,1.61)$ & 0.004 & - & - & - \\
\hline \multicolumn{6}{|c|}{ Dominant model $(\mathrm{CC}+\mathrm{CT}$ versus $\mathrm{TT})$} \\
\hline Overall & $1.30(1.11,1.53)$ & 0.002 & 0 & 0.73 & $\mathrm{~F}$ \\
\hline \multicolumn{6}{|l|}{ Race } \\
\hline Chinese Han & $1.22(1.00,1.50)$ & 0.05 & 0 & 0.90 & $\mathrm{~F}$ \\
\hline Caucasian & $1.46(1.11,1.92)$ & 0.007 & - & - & - \\
\hline \multicolumn{6}{|c|}{ Recessive model $(\mathrm{CC}$ versus $\mathrm{CT}+\mathrm{TT})$} \\
\hline Overall & $0.94(0.59,1.50)$ & 0.79 & 63 & 0.04 & $\mathrm{R}$ \\
\hline \multicolumn{6}{|l|}{ Race } \\
\hline Chinese Han & $0.70(0.34,1.44)$ & 0.34 & 52 & 0.12 & $\mathrm{R}$ \\
\hline Caucasian & $1.41(0.98,2.02)$ & 0.06 & - & - & - \\
\hline \multicolumn{6}{|c|}{ Heterozygous genetic model (CT versus TT) } \\
\hline Overall & $1.32(1.11,1.57)$ & 0.002 & 0 & 0.95 & $\mathrm{~F}$ \\
\hline \multicolumn{6}{|l|}{ Race } \\
\hline Chinese Han & $1.28(1.03,1.59)$ & 0.02 & 0 & 0.92 & $\mathrm{~F}$ \\
\hline Caucasian & $1.39(1.04,1.86)$ & 0.03 & - & - & - \\
\hline \multicolumn{6}{|c|}{ Homozygous genetic model (CC versus TT) } \\
\hline Overall & $1.13(0.71,1.80)$ & 0.60 & 56 & 0.08 & $\mathrm{R}$ \\
\hline \multicolumn{6}{|l|}{ Race } \\
\hline Chinese Han & $0.88(0.49,1.59)$ & 0.67 & 31 & 0.24 & $\mathrm{R}$ \\
\hline Caucasian & $1.69(1.14,2.51)$ & 0.009 & - & - & - \\
\hline
\end{tabular}

F: fixed-effect model; R: random-effect model; OR: odds ratio; 95\% CI: 95\% confidence interval.

genetic model $\left(I^{2}=0 \%, p=0.42\right)$. This implied that race might be a confounding factor and source of heterogeneity, whereas the pooled ORs were robust substantially.

As for heterogeneity among studies on rs187084, there was no significant heterogeneity in the allele model $\left(I^{2}=43 \%, p=0.15\right)$, dominant model $\left(I^{2}=0 \%, p=0.73\right)$, or heterozygous genetic model $\left(I^{2}=0 \%, p=0.95\right)$. However, heterogeneity was present in the recessive model $\left(I^{2}=63 \%, p=0.04\right)$ and homozygous genetic model $\left(I^{2}=56 \%, p=0.08\right)$. Similarly, a random effects model and subgroup analysis were conducted to evaluate heterogeneity. We found that the heterogeneity decreased in the Chinese Han population based on the homozygous genetic model $\left(I^{2}=31 \%, p=0.24\right)$ (Figure 6), but no significant differences were evident in the pooled results (Table 4).

3.4. Sensitivity Analysis. As mentioned before, two studies focused on rs352140 and one focused on rs187084 were not consistent with the balance of HWE in the control groups $(p<0.05)$. However, the results did not change substantially after removing them. Furthermore, a sensitivity analysis was utilized to evaluate the stability of the 


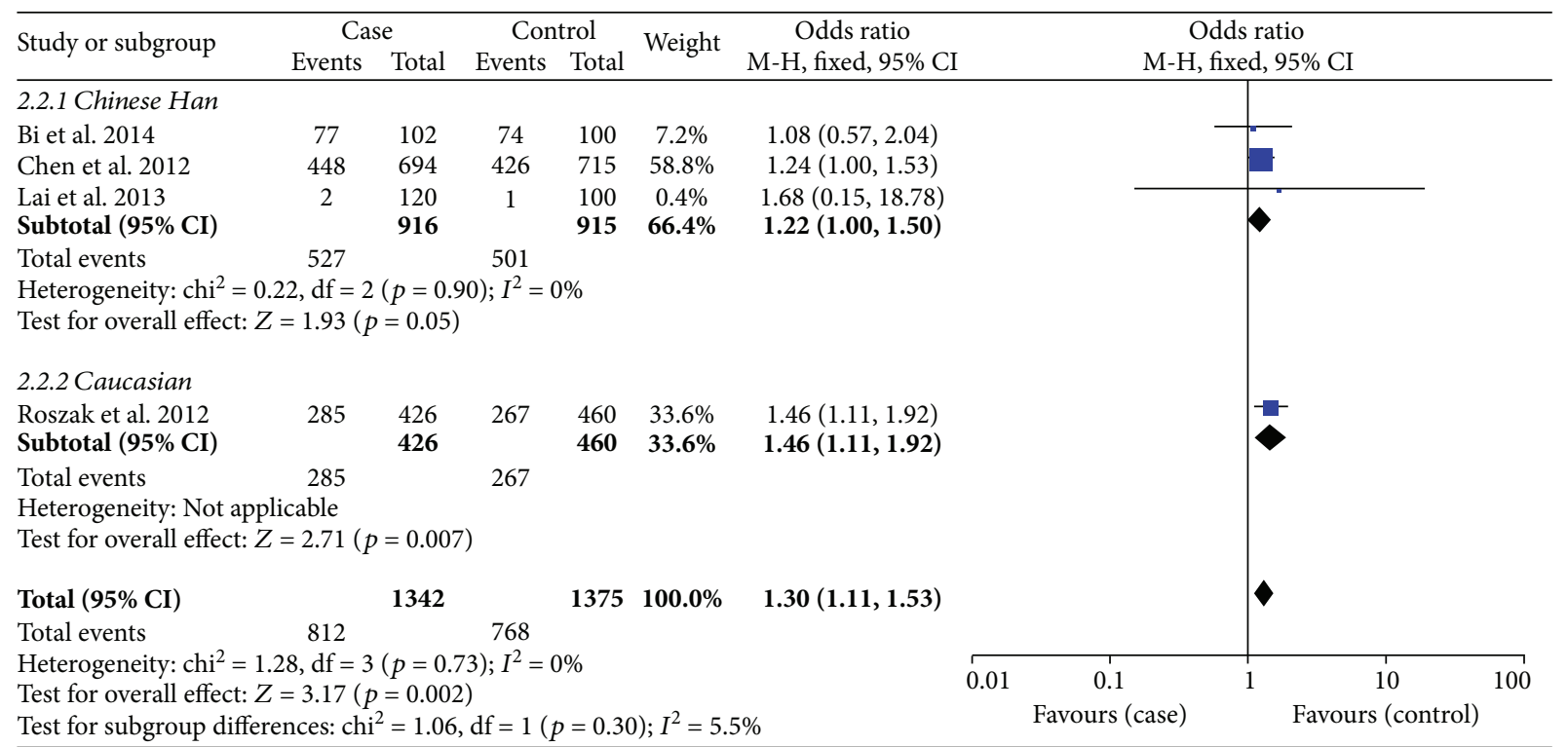

FIGURE 5: Subgroup analysis of the association between TLR9 rs187084 polymorphism and cervical cancer risk stratified by race in the dominant genetic model.

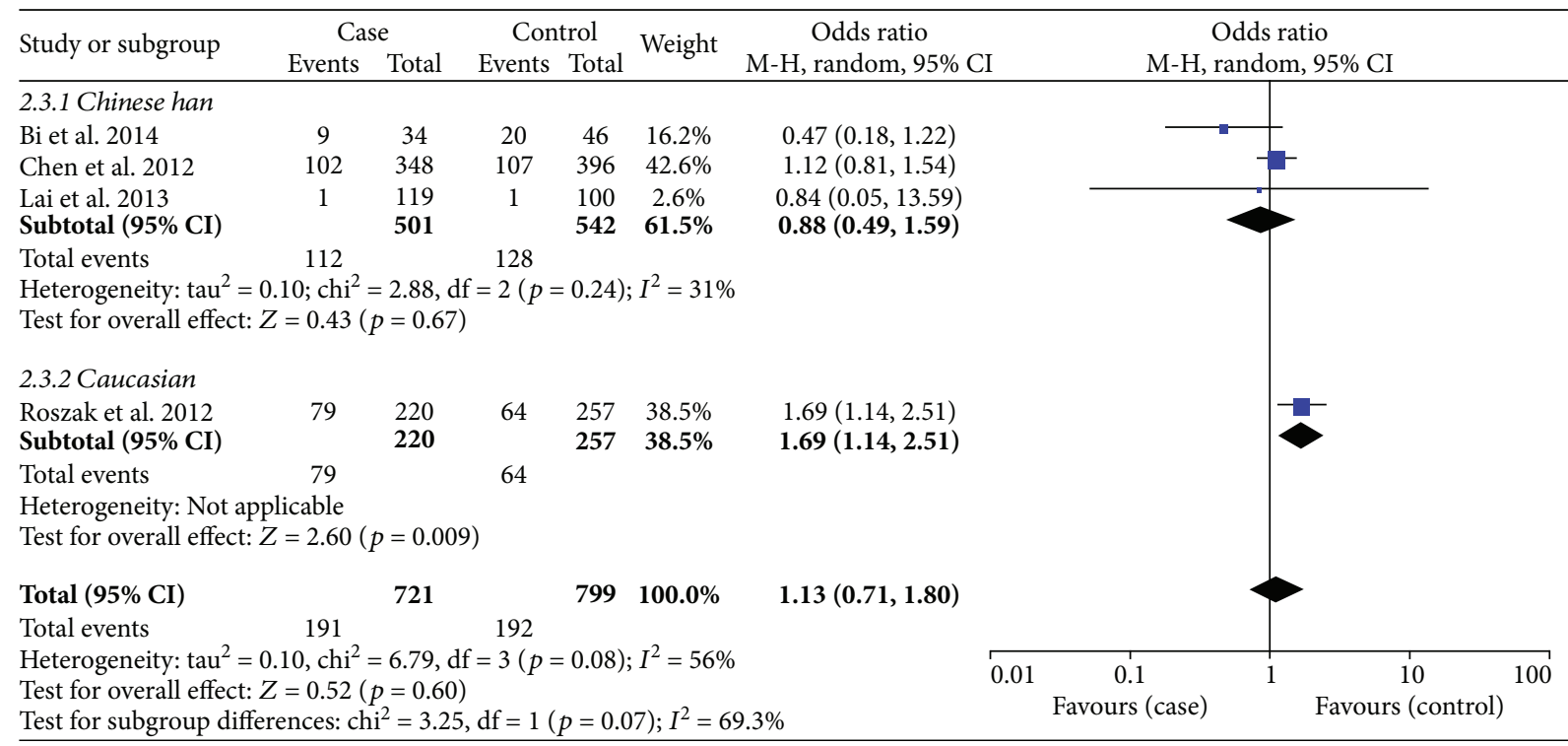

FIGURE 6: Subgroup analysis of the association between TLR9 rs187084 polymorphism and cervical cancer risk stratified by race in the homozygous genetic model.

meta-analysis by deleting all the studies one by one. However, the overall ORs did not change significantly in any of the genetic models, indicating that the meta-analysis was robust and stable. The sensitivity analysis of the associations between the two SNPs and cervical cancer susceptibility based on the dominant genetic model is shown in Figures $7(\mathrm{a})$ and $7(\mathrm{~b})$.

3.5. Publication Bias. To detect publication bias, Begg's test and Egger's test were conducted. The results showed that there was no significant evidence of publication bias for either rs352140 or rs187084 based on the five genetic models $(p>0.05)$ (Figures 8(a) and 8(b)).

\section{Discussion}

Persistent infection with HR-HPV is a causative factor in the progression of cervical cancer [21-23]. Cigarette smoking, age, and sexual activity may influence susceptibility to cervical cancer $[3,24]$.

TLR9 recognizes unmethylated CpG DNA and promotes the production of inflammatory cytokines that contribute to tumour immunity [25]. In addition, elevated TLR9 levels with persistent HPV infection can drive inflammation, thereby contributing to cervical cancer risk [26]. In recent years, a number of studies have focused on TLR9 gene polymorphisms and cervical cancer susceptibility, but the 


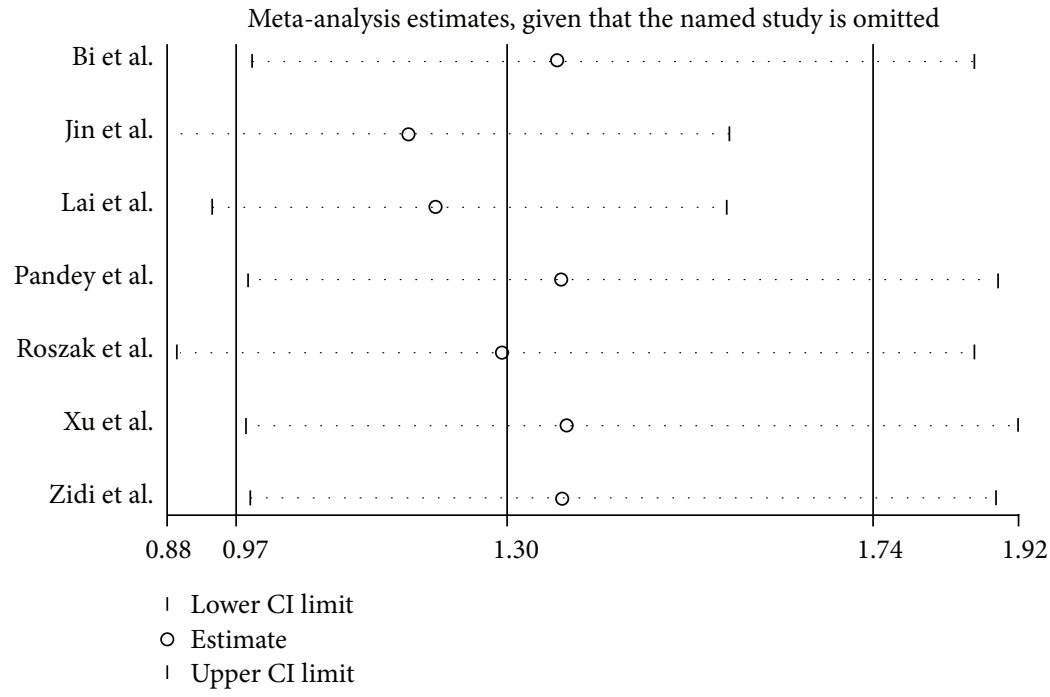

(a)

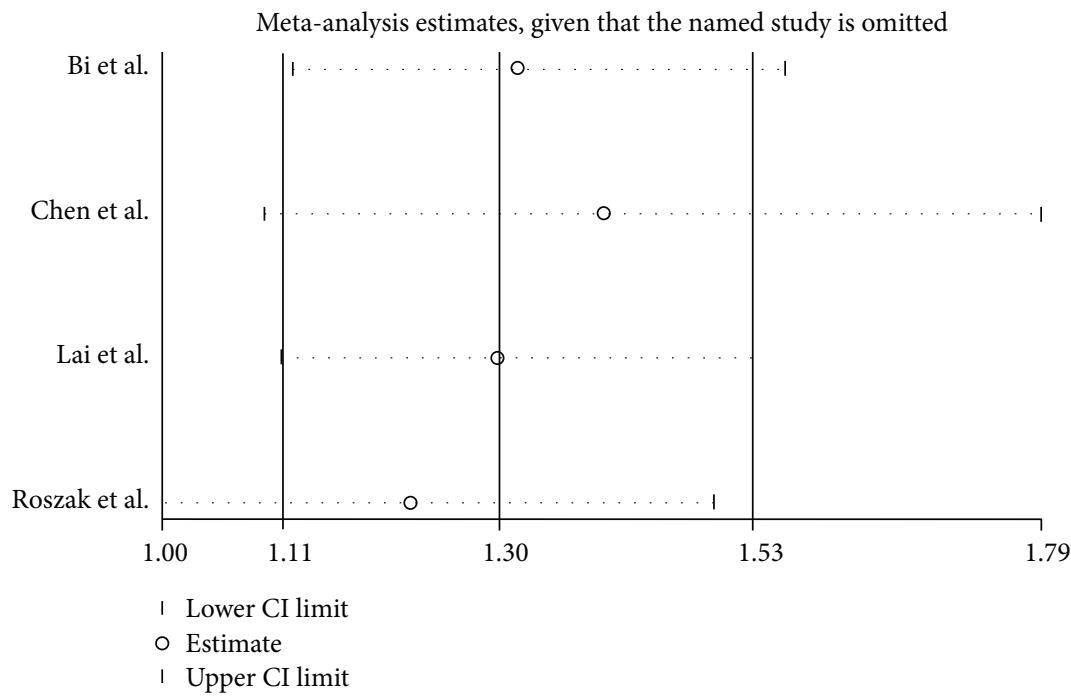

(b)

FIGURE 7: Sensitivity analysis of the association between TLR9 SNPs and risk of cervical cancer in the dominant genetic model. (a) rs352140. (b) rs 187084 .

conclusions are questionable. For rs352140, several studies revealed that rs352140 was not related to cervical cancer; however, the study of Lai et al. supported that rs352140 was associated with an increased risk of cervical cancer, and the study of Pandy et al. showed that A allele had borderline significance conferring a marginally increased risk for advanced cervical cancer $[11,15,16,18]$. With regard to rs187084, some studies indicated that rs352140 contributed to cervical cancer susceptibility, while the study of Bi et al. showed that the SNP was not associated with cervical carcinogenesis $[11,13]$. The findings were even controversial when focused on the same ethnic group. $\mathrm{Xu}$ et al. and $\mathrm{Bi}$ et al. agreed that there was no relationship between rs352140 and the risk of cervical cancer, while Lai et al. and Jin et al. held the opposite point of view $[11,14,15,18]$. Similarly, the studies of Lai et al. and $\mathrm{Bi}$ et al. indicated that $\mathrm{rs} 187084$ was not related to cervical cancer, while the study of Chen et al. supported a different conclusion $[11,13,15]$.

Our results indicated that rs352140 is not associated with cervical cancer risk, whereas rs 187084 increases susceptibility to cervical cancer. As shown in Table 4, rs187084 is associated with cervical cancer susceptibility in the allele model, dominant genetic model, and heterozygous genetic model but not in the recessive genetic model or homozygous genetic model. We postulated that the minor $\mathrm{C}$ allele at the -1486 locus might be a dominant mutation and that $\mathrm{C}$ allele carriers had an increased risk for cervical cancer. This is consistent with our conclusion that rs 187084 is a risk factor for cervical cancer. However, too many reports of associations between genetic variants and common cancer sites are false positives [27]. Therefore, assessing the false positive report probability 

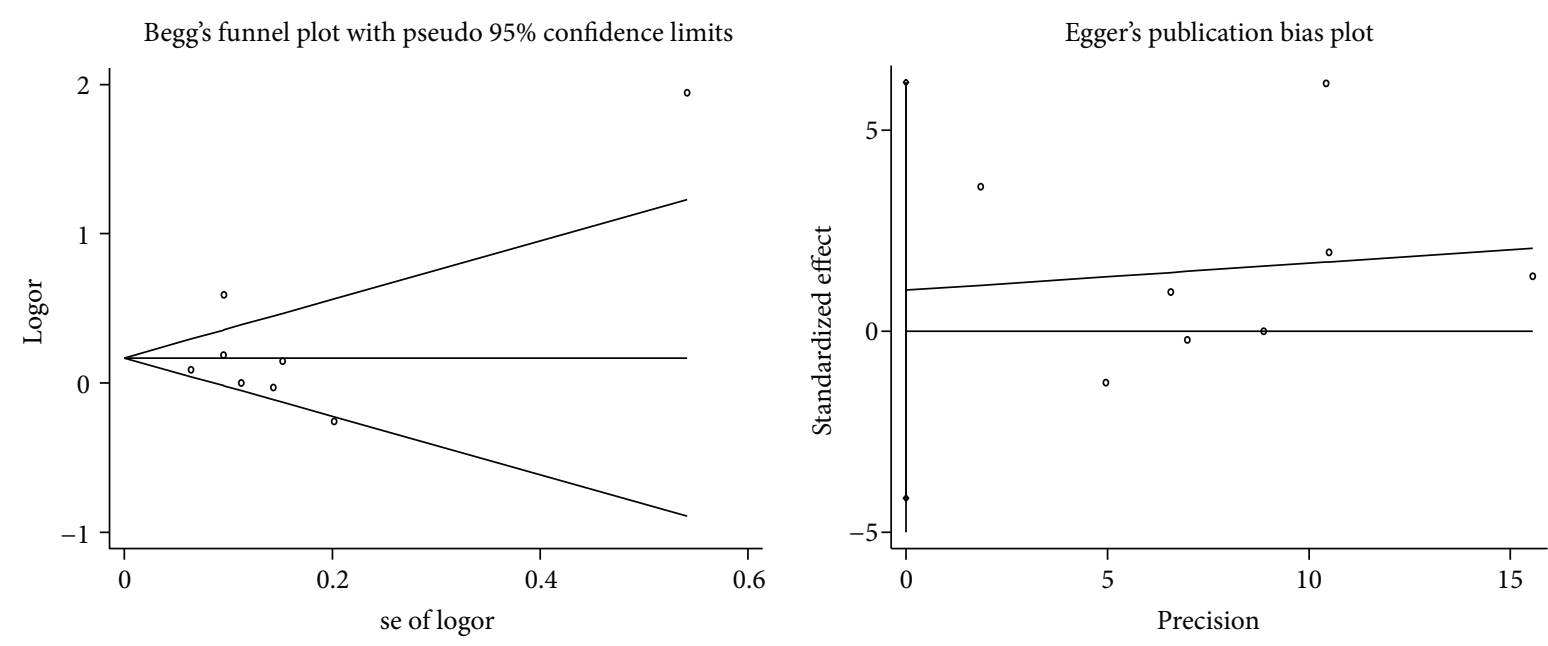

(a)

Begg's funnel plot with pseudo 95\% confidence limits
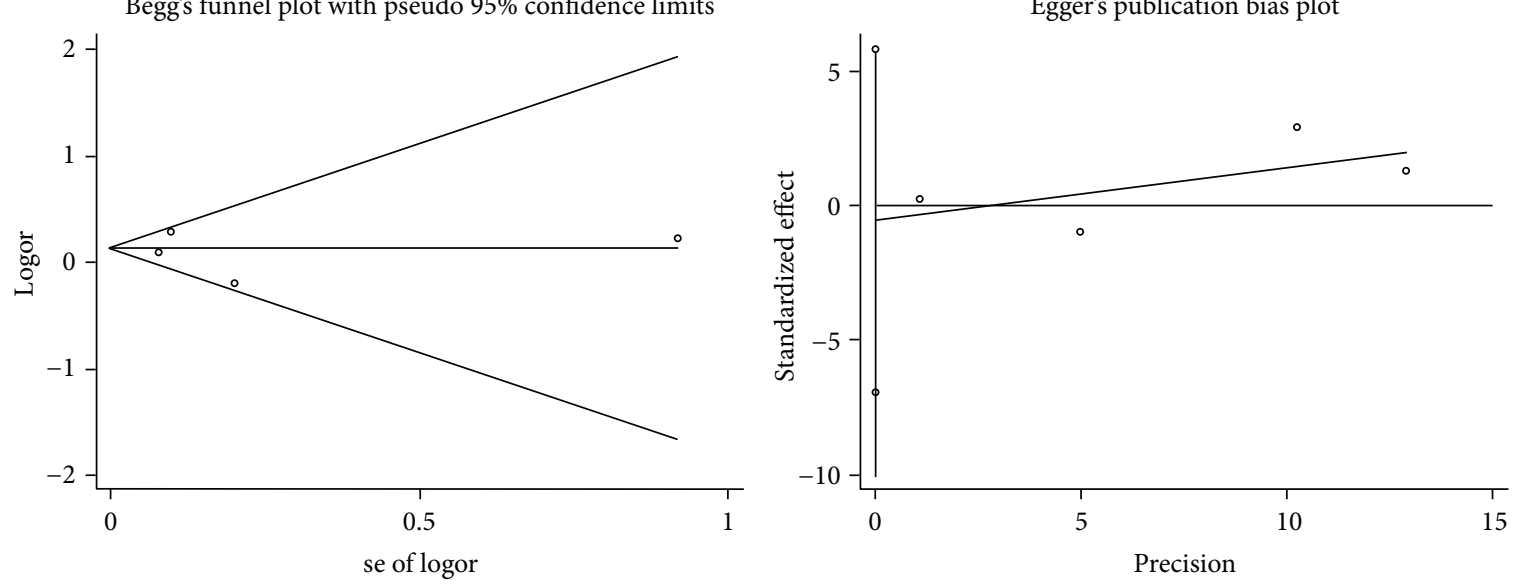

(b)

Figure 8: Publication bias of TLR9 polymorphisms in the allele model. (a) rs352140 (Begg's test: $p=1.000$, Egger's test: $p=0.647$ ). (b) rs187084 (Begg's test: $p=1.000$, Egger's test: $p=0.736$ ).

(FPRP) and using it to decide whether our finding is deserving of attention are important. Considering that our metaanalysis is a large sample and multicentre study, we applied 0.2 as the cut-off value for FPRP. According to Wacholder's method, we evaluated the FPRPs for the dominant model $(\mathrm{CC}+\mathrm{CT}$ versus TT) and heterozygous genetic model (CT versus TT). The FPRPs were 0.142 and 0.154 , respectively [27]. Obviously, both FPRP results were below the cut-off value, suggesting that rs187084 is related to cervical cancer susceptibility and that our conclusion is noteworthy.

Subgroup analysis of rs352140 showed a significant decline in heterogeneity in the Caucasian population, implying that the heterogeneity may result from racial differences. Moreover, it was statistically significant that the A allele elevated the cervical cancer risk in the allele genetic model $(\mathrm{OR}=1.11, p=0.03)$ while the pooled results in other genetic models remained steady. The evaluated FPRP was 0.751, which was greater than 0.2 , implying a false positive association between rs352140 and cervical cancer risk among the Caucasian population [27]. Subgroup analysis and sensitivity analysis of rs187084 were also conducted. The pooled results remained identical, presenting an obvious association between rs187084 and increased cervical cancer risk and suggesting that our meta-analysis results were reliable and stable.

We searched for TLR9 SNPs in the NCBI database and found that rs352140 was a synonymous codon. This, to some extent, explained the reason for the lack of relevance regarding cervical cancer risk. It has been identified that regulatory polymorphisms controlling gene expression can be localized hundreds of $\mathrm{kb}$ away from the genes they influence $[28,29]$. In this way, rs187084 is potentially a functional variant located in the TLR9 promoter region; so, we propose that this SNP contributes to the regulation of TLR9 at a basal transcript level [30, 31]. Moreover, rs187084 is located near the region that interacts with the HPV16 E6 and E7 oncoproteins [32]. Therefore, it may regulate transcription during HR-HPV infection and increase the risk of cervical cancer. TLR9 plays a fundamental role in pathogen recognition and the activation of innate immunity and was found to be overexpressed in cervical cancer $[33,34]$. IFN $-\gamma$ and TNF- $\alpha$ are 
two important cytokines that participate in the innate immune response. In addition to this, they stimulate antigen-presenting cells to express MHC II, enhancing antigen presentation and improving the adaptive immune response. The minor $\mathrm{C}$ allele of rs187084 led to significantly lower expression of protective cytokines IFN- $\gamma$ and TNF- $\alpha$ than the $\mathrm{T}$ allele [35]. In addition, rs $187084 \mathrm{C}$ allele increased the transcriptional activity of TLR9 and provoked a higher level of gene expression $[35,36]$.

A previous meta-analysis on the relationship between TLR9 polymorphisms rs352140 and rs187084 and cervical cancer risk conducted by $\mathrm{Mu}$ et al. is consistent with our results [37]. There were five studies of rs352140 and four case-control studies of rs187084 in the study of $\mathrm{Mu}$ et al. that assessed the correlation between TLR9 SNPs and cervical cancer risk. Compared to the study of $\mathrm{Mu}$ et al., our meta-analysis included three additional qualified studies $[14,18,19]$ to assess the association and therefore obtained more reliable and persuasive conclusions. Moreover, in order to reduce the heterogeneity caused by racial differences, we performed a subgroup analysis stratified by race. Thus, our findings are more convincing and rigorous.

Several limitations are present in our meta-analysis. First, even though we retrieved records from electronic databases systematically, there were likely still some unpublished studies we could not acquire because of their negative results, leading to potential bias. Second, the incidence of cervical cancer is highest in sub-Saharan Africa, Latin America, the Caribbean, and Melanesia, where people of African origin account for the majority [1]. However, there were no statistics and studies of interest focused on men of African descent even though several databases were searched. This led to our study focusing on Caucasian and Chinese Han populations, resulting in a bias in the relationship that we are concerned. Additionally, although we considered the effect of HPV on our conclusions and attempted to perform a subgroup analysis, few of the included studies contained HPV data. Therefore, we were unable to conduct a subgroup analysis on HPV infection. Future studies containing more comprehensive information are needed to obtain more reliable conclusions.

In conclusion, this meta-analysis demonstrated that there is no association between TLR9 rs352140 (G2848A) and cervical cancer susceptibility, while rs $187084(-1486 \mathrm{~T} / \mathrm{C})$ has a statistical correlation with the risk of cervical cancer. The rs187084 C allele is considered a deleterious allele and increases cervical cancer risk. Further large, well-designed case-control studies are needed to authenticate these results.

\section{Data Availability}

The data used to support the findings of this study are available from the corresponding author upon request.

\section{Conflicts of Interest}

The authors declare that there is no conflict of interest regarding the publication of this paper.

\section{Acknowledgments}

The research is supported by the National Natural Science Foundation of China (no. 81472428) and New Century Excellent Talents in University (NCET-12-0441).

\section{References}

[1] L. A. Torre, F. Bray, R. L. Siegel, J. Ferlay, J. Lortet-Tieulent, and A. Jemal, "Global cancer statistics, 2012," CA: A Cancer Journal for Clinicians, vol. 65, no. 2, pp. 87-108, 2015.

[2] W. Chen, R. Zheng, P. D. Baade et al., "Cancer statistics in China, 2015," CA: A Cancer Journal for Clinicians, vol. 66, no. 2, pp. 115-132, 2016.

[3] Q. Zhang, W. Xie, F. Wang et al., "Epidemiological investigation and risk factors for cervical lesions: cervical cancer screening among women in rural areas of Henan province China," Medical Science Monitor, vol. 22, pp. 1858-1865, 2016.

[4] N. Muñoz, F. X. Bosch, S. de Sanjosé et al., "Epidemiologic classification of human papillomavirus types associated with cervical cancer," The New England Journal of Medicine, vol. 348, no. 6, pp. 518-527, 2003.

[5] S. de Sanjose, M. Diaz, X. Castellsague et al., "Worldwide prevalence and genotype distribution of cervical human papillomavirus DNA in women with normal cytology: a meta-analysis," The Lancet Infectious Diseases, vol. 7, no. 7, pp. 453-459, 2007.

[6] M. Zhao, Y. Li, X. Wei et al., "Negative immune factors might predominate local tumor immune status and promote carcinogenesis in cervical carcinoma," Virology Journal, vol. 14, no. 1, p. $5,2017$.

[7] A. M. Mehta, M. Mooij, I. Branković, S. Ouburg, S. A. Morré, and E. S. Jordanova, "Cervical carcinogenesis and immune response gene polymorphisms: a review," Journal of Immunology Research, vol. 2017, 12 pages, 2017.

[8] Y. Hao, J. L. Yuan, A. Abudula, A. Hasimu, N. Kadeer, and X. Guo, "TLR9 expression in uterine cervical lesions of Uyghur women correlate with cervical cancer progression and selective silencing of human papillomavirus 16 E6 and E7 oncoproteins in vitro," Asian Pacific Journal of Cancer Prevention, vol. 15, no. 14, pp. 5867-5872, 2014.

[9] U. A. Hasan, E. Bates, F. Takeshita et al., "TLR9 expression and function is abolished by the cervical cancer-associated human papillomavirus type 16," Journal of Immunology, vol. 178, no. 5, pp. 3186-3197, 2007.

[10] G.-X. Wan, Y. W. Cao, W. Q. Li, Y. C. Li, W. J. Zhang, and F. Li, "Associations between TLR9 polymorphisms and cancer risk: evidence from an updated meta-analysis of 25,685 subjects," Asian Pacific Journal of Cancer Prevention, vol. 15, no. 19, pp. 8279-8285, 2014.

[11] X. Bi, X. H. Xu, and X. Yu, "Study on TLRs polymorphisms and cervical cancer susceptibility," Progress in Obstetrics \& Gynecology, vol. 23, no. 7, pp. 520-523, 2014.

[12] C. Bodelon, M. M. Madeleine, L. G. Johnson et al., "Genetic variation in the TLR and NF- $\kappa \mathrm{B}$ pathways and cervical and vulvar cancer risk: a population-based case-control study," International Journal of Cancer, vol. 134, no. 2, pp. 437-444, 2014.

[13] X. Chen, S. Wang, L. Liu et al., "A genetic variant in the promoter region of Toll-like receptor 9 and cervical cancer susceptibility," DNA and Cell Biology, vol. 31, no. 5, pp. 766$771,2012$. 
[14] Y. Jin, S. Qiu, N. Shao, and J. Zheng, “Association of toll-like receptor gene polymorphisms and its interaction with HPV infection in determining the susceptibility of cervical cancer in Chinese Han population," Mammalian Genome, vol. 28, no. 5-6, pp. 213-219, 2017.

[15] Z.-Z. Lai, Ni-Zhang, X. L. Pan, and L. Song, “Toll-like receptor 9 (TLR9) gene polymorphisms associated with increased susceptibility of human papillomavirus-16 infection in patients with cervical cancer," The Journal of International Medical Research, vol. 41, no. 4, pp. 1027-1036, 2013.

[16] S. Pandey, B. Mittal, M. Srivastava et al., "Evaluation of Toll-like receptors 3 (c.1377C/T) and 9 (G2848A) gene polymorphisms in cervical cancer susceptibility," Molecular Biology Reports, vol. 38, no. 7, pp. 4715-4721, 2011.

[17] A. Roszak, M. Lianeri, A. Sowińska, and P. P. Jagodziński, "Involvement of toll-like receptor 9 polymorphism in cervical cancer development," Molecular Biology Reports, vol. 39, no. 8, pp. 8425-8430, 2012.

[18] X. Xu, C. Yin, Z. Yan, Y. Hu, and Z. Yang, "The correlation of TLR9 gene polymorphism with occurrence and development of cervical cancer in Yunnan Han population," Journal of Guizhou Medical University, vol. 1, pp. 21-25, 2017.

[19] S. Zidi, I. Sghaier, E. Gazouani, A. Mezlini, and B. YacoubiLoueslati, "Evaluation of Toll-like receptors 2/3/4/9 gene polymorphisms in cervical cancer evolution," Pathology Oncology Research, vol. 22, no. 2, pp. 323-330, 2016.

[20] G. A. Wells, B. J. Shea, D. O'Connell et al., "The NewcastleOttawa Scale (NOS) for assessing the quality of nonrandomized studies in meta-analysis," Available at : http:// www.ohri.ca/programs/clinical_epidemiology/oxford.asp.

[21] S.-J. Lee, A. Yang, T.-C. Wu, and C.-F. Hung, "Immunotherapy for human papillomavirus-associated disease and cervical cancer: review of clinical and translational research," Journal of Gynecologic Oncology, vol. 27, no. 5, 2016.

[22] X. Castellsagué, "Natural history and epidemiology of HPV infection and cervical cancer," Gynecologic Oncology, vol. 110, no. 3, pp. S4-S7, 2008.

[23] S. S. Wang, P. Gonzalez, K. Yu et al., "Common genetic variants and risk for HPV persistence and progression to cervical cancer," PLoS One, vol. 5, no. 1, article e8667, 2010.

[24] S. Campino, J. Forton, S. Auburn et al., "TLR9 polymorphisms in African populations: no association with severe malaria, but evidence of cis-variants acting on gene expression," Malaria Journal, vol. 8, no. 1, p. 44, 2009.

[25] S. Cornélie, J. Hoebeke, A. M. Schacht et al., "Direct evidence that Toll-like receptor 9 (TLR9) functionally binds plasmid DNA by specific cytosine-phosphate-guanine motif recognition," The Journal of Biological Chemistry, vol. 279, no. 15, pp. 15124-15129, 2004.

[26] F. Cannella, A. Pierangeli, C. Scagnolari et al., "TLR9 is expressed in human papillomavirus-positive cervical cells and is overexpressed in persistent infections," Immunobiology, vol. 220, no. 3, pp. 363-368, 2015.

[27] S. Wacholder, S. Chanock, M. Garcia-Closas, L. El Ghormli, and N. Rothman, "Assessing the probability that a positive report is false: an approach for molecular epidemiology studies," Journal of the National Cancer Institute, vol. 96, no. 6, pp. 434-442, 2004.

[28] B. E. Stranger, A. C. Nica, M. S. Forrest et al., "Population genomics of human gene expression," Nature Genetics, vol. 39, no. 10, pp. 1217-1224, 2007.
[29] J. T. Forton, I. A. Udalova, S. Campino, K. A. Rockett, J. Hull, and D. P. Kwiatkowski, "Localization of a long-range cisregulatory element of IL13 by allelic transcript ratio mapping," Genome Research, vol. 17, no. 1, pp. 82-87, 2006.

[30] K. Tao, M. Fujii, S. I. Tsukumo et al., "Genetic variations of Toll-like receptor 9 predispose to systemic lupus erythematosus in Japanese population," Annals of the Rheumatic Diseases, vol. 66, no. 7, pp. 905-909, 2007.

[31] M. W. Ng, C. S. Lau, T. M. Chan, W. H. S. Wong, and Y. L. Lau, "Polymorphisms of the toll-like receptor 9 (TLR9) gene with systemic lupus erythematosus in Chinese," Rheumatology, vol. 44, no. 11, pp. 1456-1457, 2005.

[32] L. Hamann, C. Glaeser, A. Hamprecht, M. Gross, A. Gomma, and R. R. Schumann, "Toll-like receptor (TLR)-9 promotor polymorphisms and atherosclerosis," Clinica Chimica Acta, vol. 364, no. 1-2, pp. 303-307, 2006.

[33] C. Martínez-Campos, M. Bahena-Román, K. Torres-Poveda, A. I. Burguete-García, and V. Madrid-Marina, "TLR9 gene polymorphism $-1486 \mathrm{~T} / \mathrm{C}$ ( $\mathrm{rs} 187084)$ is associated with uterine cervical neoplasm in Mexican female population," Journal of Cancer Research and Clinical Oncology, vol. 143, no. 12, pp. 2437-2445, 2017.

[34] E. Fehri, E. Ennaifer, M. Ardhaoui et al., "Expression of Tolllike receptor 9 increases with progression of cervical neoplasia in Tunisian women - a comparative analysis of condyloma, cervical intraepithelial neoplasia and invasive carcinoma," Asian Pacific Journal of Cancer Prevention, vol. 15, no. 15, pp. 6145-6150, 2014.

[35] D. Bharti, A. Kumar, R. S. Mahla et al., "The role of TLR9 polymorphism in susceptibility to pulmonary tuberculosis," Immunogenetics, vol. 66, no. 12, pp. 675-681, 2014.

[36] J. Fischer, A. N. R. Weber, S. Böhm et al., "Sex-specific effects of TLR9 promoter variants on spontaneous clearance of HCV infection,” Gut, vol. 66, no. 10, pp. 1829-1837, 2017.

[37] X. Mu, J. Zhao, X. Yuan et al., "Gene polymorphisms of Tolllike receptor 9-1486T/C and 2848G/A in cervical cancer risk," International Journal of Gynecological Cancer, vol. 25, no. 7, pp. 1173-1178, 2015. 


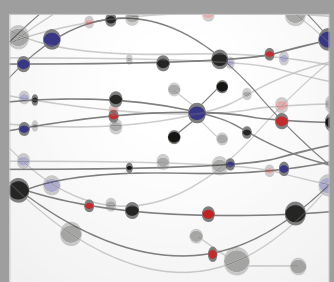

The Scientific World Journal
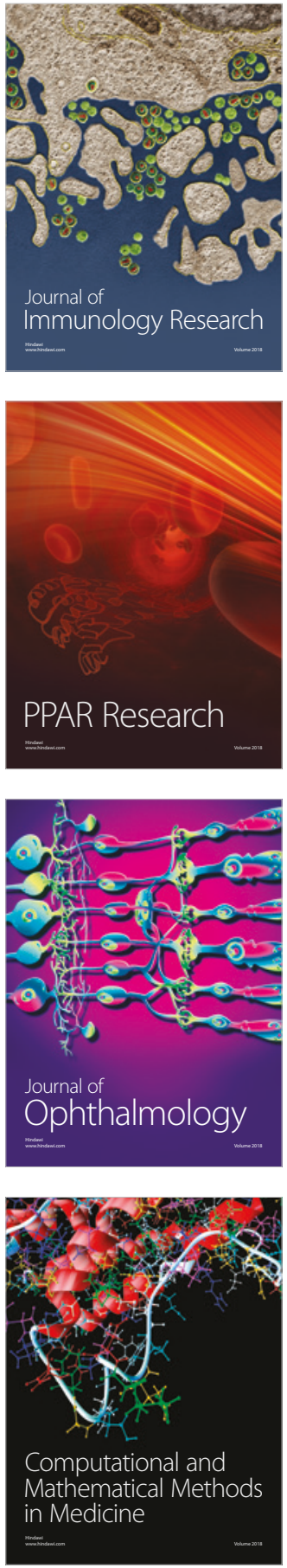

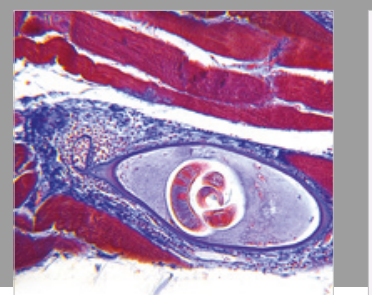

Gastroenterology Research and Practice

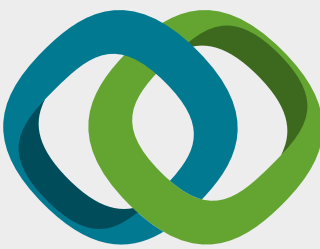

\section{Hindawi}

Submit your manuscripts at

www.hindawi.com
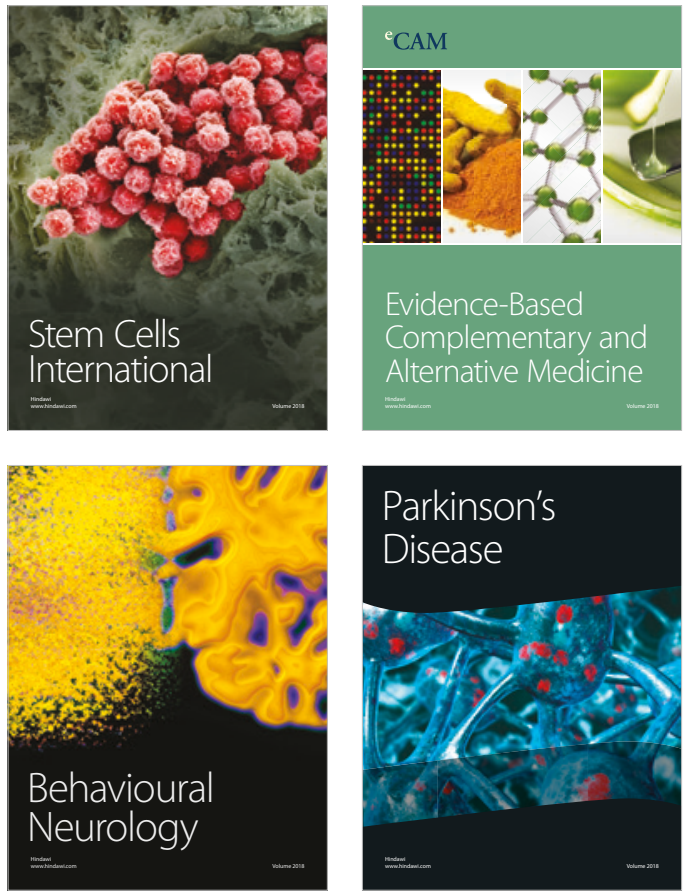

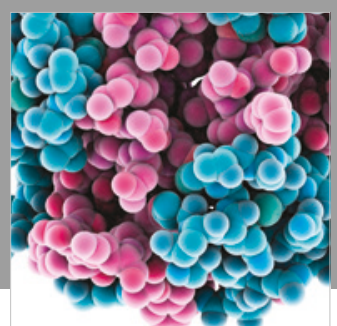

ournal of

Diabetes Research

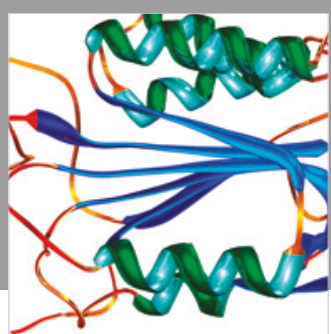

Disease Markers
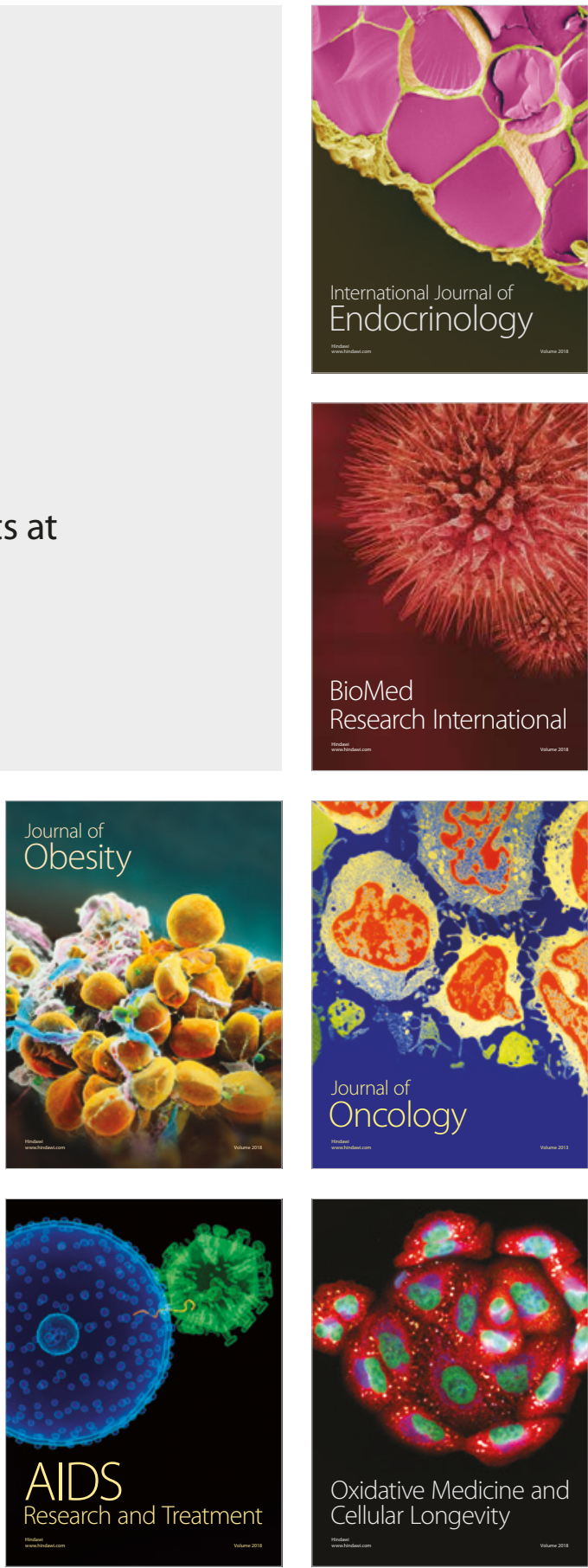